\title{
New radiosensitization treatment (KORTUC I) using hydrogen peroxide solution-soaked gauze bolus for unresectable and superficially exposed neoplasms
}

\author{
YASUHIRO OGAWA ${ }^{1}$, HIRONOBU UE $^{1}$, KAZUHIRO TSUZUKI $^{1}$, MICHIKO TADOKORO ${ }^{1}$, \\ KANA MIYATAKE ${ }^{1}$, TOSHIKAZU SASAKI ${ }^{1}$, NORIKAZU YOKOTA ${ }^{1}$, NORIHIKO HAMADA ${ }^{1}$, \\ SHINJI KARIYA ${ }^{1}$, JIRO HITOMI ${ }^{1}$, AKIHITO NISHIOKA ${ }^{1}$, KIMIKO NAKAJIMA ${ }^{2}$, \\ MITSUNORI IKEDA ${ }^{2}$, SHIGETOSHI SANO ${ }^{2}$ and TAISUKE INOMATA ${ }^{3}$ \\ Departments of ${ }^{1}$ Diagnostic Radiology and Radiation Oncology, ${ }^{2}$ Dermatology, Medical School, Kochi \\ University, Kochi 783-8505; ${ }^{3}$ Department of Radiology, Osaka Medical College, Osaka 569-8686, Japan
}

Received December 3, 2007; Accepted February 20, 2008

\begin{abstract}
We developed a new radiosensitization treatment using a hydrogen peroxide solution (Oxydol)-soaked gauze named KORTUC I (Kochi Oxydol-Radiation Therapy for Unresectable Carcinomas) for superficially exposed and unresectable neoplasms, such as malignant melanoma and malignant fibrous histiocytoma (MFH), based on our experimental results which demonstrated hydrogen peroxide as a strong radiosensitizer for the highly radioresistant osteosarcoma cell line, HS-Os-1. Five patients entered our clinical trial, one of whom had unresectable malignant melanoma; one, unresectable MFH; one, unresectable extramammary Paget's disease; one, locally advanced breast cancer and one with locally recurrent skin cancer. These patients were treated with radiation therapy using a high-energy electron beam from a linear accelerator. The total dose was $48 \mathrm{~Gy}$, and each fraction size was $4 \mathrm{~Gy}$. Radiation therapy for these patients was performed three times per week. Each time the radiation therapy was carried out, the superficially exposed tumors of these patients were covered with hydrogen peroxide solution (Oxydol)-soaked gauze, and the lesion was gently massaged for several minutes so as to allow the hydrogen peroxide solution to soak deeply into the tumor. In the treatment results, two of these five patients showed a clinically complete response (cCR) two to three months following the end of the KORTUC I radiosensitization treatment. The other three
\end{abstract}

Correspondence to: Dr Yasuhiro Ogawa, Department of Diagnostic Radiology and Radiation Oncology, Medical School, Kochi University, Oko-cho, Nankoku-shi, Kochi-Prefecture 7838505, Japan

E-mail: ogaway@kochi-u.ac.jp

Key words: hydrogen peroxide, radiotherapy, radiosensitization, malignant melanoma, malignant fibrous histiocytoma patients showed a clinically partial response (cCR) showing a decrement of more than half of the pretreatment volume. KORTUC I was completed without any severe complications, excluding mild radiation-induced dermatitis/ mucositis (Grade I). In conclusion, this newly developed radiosensitization treatment using hydrogen peroxide solution (Oxydol)-soaked gauze for superficially exposed unresectable/ radioresistant neoplasms appears to be an effective and valuable method of radiosensitization in terms of the blockade of anti-oxidative enzymes such as peroxidases, resulting in local oxygen production. Moreover, the KORTUC I radiosensitization treatment is relatively inexpensive and the method can therefore be utilized worldwide for many patients suffering from superficially exposed and locally advanced radioresistant neoplasms such as malignant melanoma, malignant fibrous histiocytoma (MFH) and various types of sarcomas.

\section{Introduction}

Although various methods of radiosensitizing treatment for radioresistant neoplasms have been developed (1-5), a clinically available method has yet to be established. Therefore, herein we introduce a new radiosensitizing treatment using hydrogen peroxide solution (Oxydol), named KORTUC (Kochi Oxydol-Radiation Therapy for Unresectable Carcinomas), for patients with superficially exposed and locally advanced unresectable neoplasms. Our new KORTUC I radiosensitizing treatment was developed based on our experimental results which demonstrated the powerful radiosensitizing effects of hydrogen peroxide for the highly radioresistant osteosarcoma cell line, HS-Os-1 (6-8). In our experiments, although the osteosarcoma cell line HS-Os-1 showed almost no production of reactive oxygen species (ROS) and almost no cell damage morphologically against $30 \mathrm{~Gy}$ of X-ray irradiation, apoptosis of the cell line was easily induced following $10 \mathrm{~Gy}$ of X-ray irradiation in the presence of low hydrogen peroxide concentrations $(0.1 \mathrm{mM})$ in the medium at the time of irradiation. Therefore, the 
Table I. Summarized data of the patients treated with KORTUC I.

\begin{tabular}{|c|c|c|c|c|c|c|}
\hline Case no. & Age & Gender & Disease & Site & Treatment effect & Time to progression \\
\hline 1 & 73 & M & $\begin{array}{l}\text { Malignant } \\
\text { melanoma (recurrent) }\end{array}$ & Right leg & $\mathrm{cCR}$ & Locally controlled $>12$ months \\
\hline 2 & 87 & M & $\begin{array}{l}\text { Malignant } \\
\text { fibrous histiocytoma } \\
\text { (MFH) (recurrent) }\end{array}$ & $\begin{array}{l}\text { Lower } \\
\text { abdomen }\end{array}$ & $\mathrm{cPR}$ & 6 months \\
\hline 3 & 63 & $\mathrm{~F}$ & $\begin{array}{l}\text { Extramammary } \\
\text { Paget's disease } \\
\text { (recurrent) }\end{array}$ & Perineum & $\mathrm{cCR}$ & Locally controlled $>12$ months \\
\hline 4 & 51 & $\mathrm{~F}$ & $\begin{array}{l}\text { Locally advanced } \\
\text { breast cancer }\end{array}$ & $\begin{array}{l}\text { Right } \\
\text { breast }\end{array}$ & $\mathrm{cPR}$ & 5 months \\
\hline 5 & 66 & $\mathrm{~F}$ & $\begin{array}{l}\text { Advanced skin } \\
\text { cancer (SCC) } \\
\text { (recurrent) }\end{array}$ & $\begin{array}{l}\text { Right } \\
\text { inguinal } \\
\text { region }\end{array}$ & $\mathrm{cPR}$ & 6 months \\
\hline
\end{tabular}

powerful effects of hydrogen peroxide as a radiosensitizer were elucidated in our experiments, and we intend to apply the radiosensitizing effects of hydrogen peroxide for clinical use for patients with superficially exposed and locally advanced radioresistant neoplasms. In the present study, we have shown that this highly effective radiosensitization method can be carried out with the use of a hydrogen peroxide solution (Oxydol)-soaked gauze for patients with the disease states described above. Since there are many more patients with non-superficially exposed neoplasms such as breast cancer, hepatocellular carcinoma and pancreatic cancer, the development of a new radiosensitizer for topical tumor injection is considered to be essential. We have already developed such a radiosensitizer that can be injected into human tumor tissue under an ultrasonographic guide and we will report on the clinical application of this new agent.

\section{Materials and methods}

Informed consent was obtained from the five patients who entered into our clinical trial of KORTUC I (Kochi OxydolRadiation Therapy for Unresectable Carcinomas, Type I). The KORTUC I trial was approved by our local ethics committee.

One of the five patients had post-operatively relapsed malignant melanoma on his right leg, and the lesion was in an unresectable state; one had recurrent and unresectable MFH (malignant fibrous histiocytoma) on the left lower abdomen; one had extramammary Paget's disease of postoperative relapse and urethral invasion; one had locally highly advanced left breast cancer in an already unresectable state and another one had recurrent and unresectable squamous cell carcinoma on the right femoral region.

For these patients, radiation therapy with a high-energy electron beam at an appropriate energy level depending on the depth of each lesion from an EXL-20TP linear accelerator (Mitsubishi Electric Co. Ltd., Tokyo, Japan), was performed with a total dose of $48 \mathrm{~Gy}$, with each fraction size being $4 \mathrm{~Gy}$.
The radiation therapy was performed three times a week. Each time the irradiation was carried out, the surface of the tumor of each patient was totally covered with hydrogen peroxide solution (Oxydol)-soaked gauze bolus, and the lesion was gently massaged for several minutes so as to allow the hydrogen peroxide solution to soak deeply into the tumor, as shown in Fig. 1.

In order to avoid skin-sparing (build-up) phenomenon characteristic of high-energy electron beams, a water-soaked gauze bolus is commonly used in electron irradiation for superficial neoplasms such as skin cancer. However, in light of the need for disinfection and radiosensitization, we covered the surface of the tumor with gauze soaked in hydrogen peroxide solution (Oxydol) instead of water at each radiation therapy, as an Oxydol-gauze bolus. Oxydol is a disinfectant for superficial lesions used worldwide, and contains $2.5-3.5 \%$ of hydrogen peroxide.

\section{Results}

The summarized data of the five patients who entered the KORTUC I trial are shown in Table I. The KORTUC I treatment was safely performed without any severe complications, excluding mild radiation-induced dermatitis/mucositis for all five patients.

In two of the five patients, the lesions almost completely disappeared two to three months following the end of our newly developed KORTUC I radiosensitization treatment and the treatment effects were evaluated as a clinically complete response (cCR). The lesions of the other patients with MFH, locally advanced breast cancer and unresectable skin cancer, respectively, showed a decrement of more than half of the pretreatment volume, and the treatment effect was evaluated as a clinically partial response (cPR).

In Fig. 2, the changes regarding the local findings of the patient (73-year-old male) with recurrent and unresectable malignant melanoma are shown. The large tumor on the 


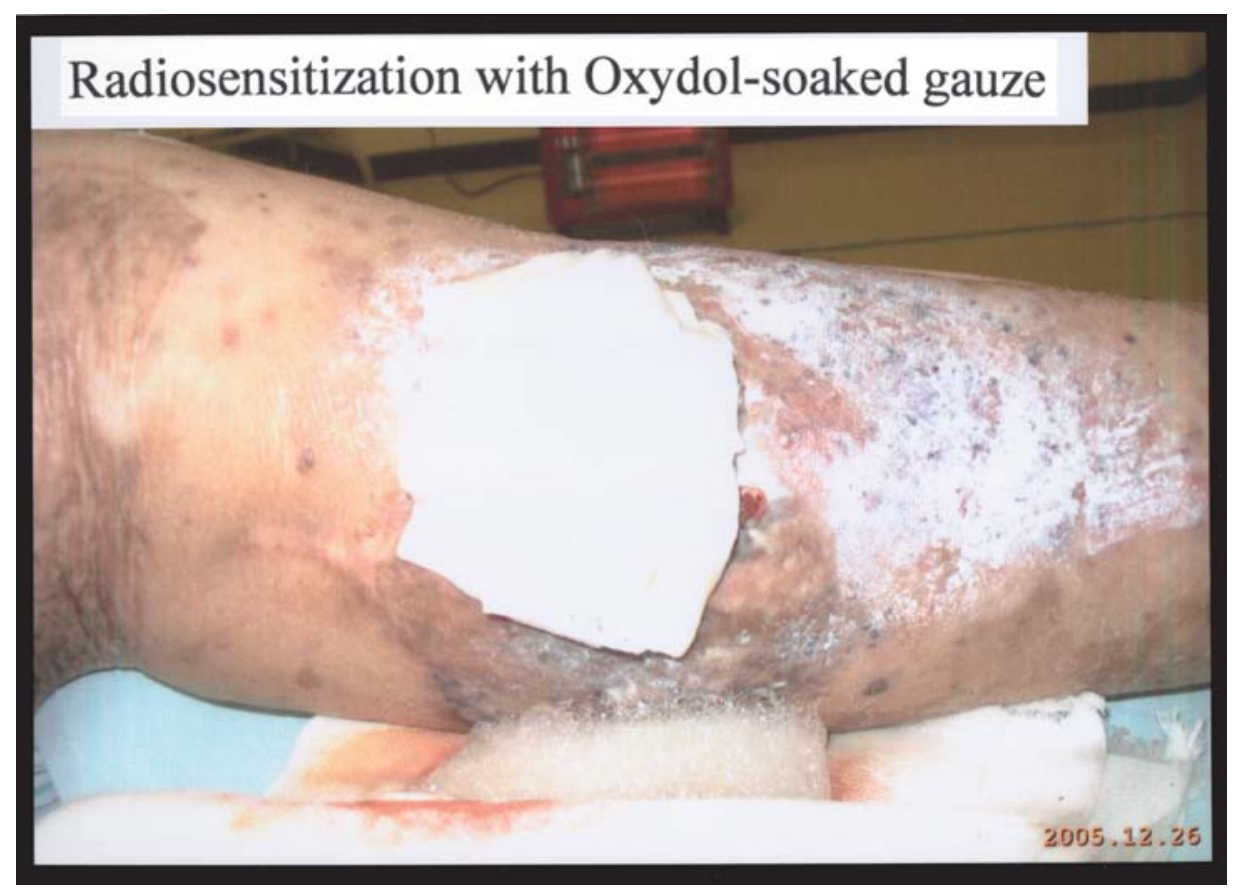

Figure 1. The surface of the tumor of each patient was totally covered with hydrogen peroxide solution (Oxydol)-soaked gauze bolus, and abundant bubbles of oxygen produced by the degradation of hydrogen peroxide by peroxidase are shown at the bottom on the figure.

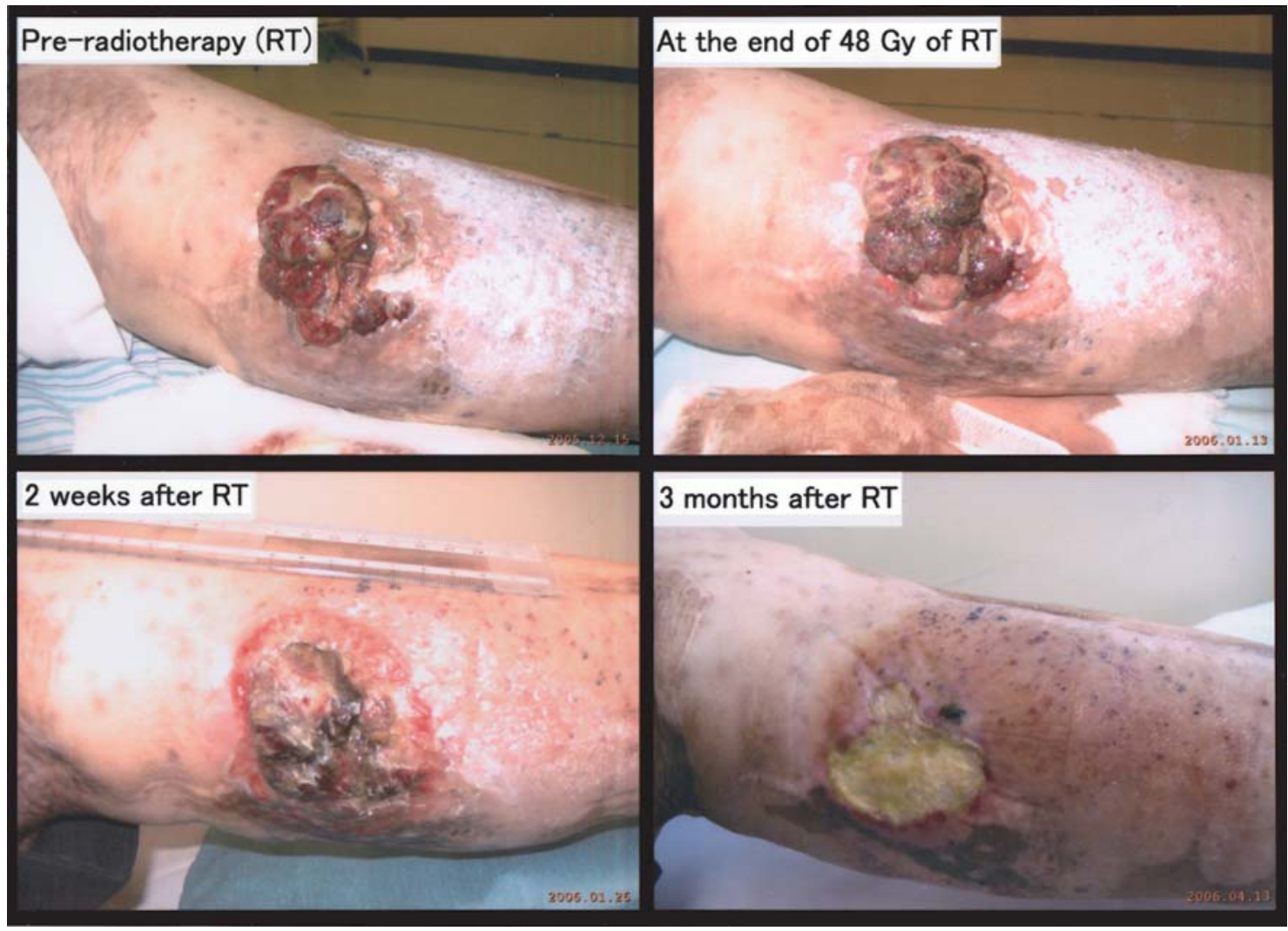

Figure 2. The changes regarding the local findings of the patient (73-year-old male) with recurrent and unresectable malignant melanoma are shown.

patient's right leg had completely disappeared 3 months following the end of the KORTUC I radiosensitization treatment.
In Fig. 3, the changes regarding the local findings of the patient (87-year-old male) with unresectable malignant fibrous histiocytoma are shown. The large tumor on the patient's left lower abdomen showed a decrement of more than half of the 


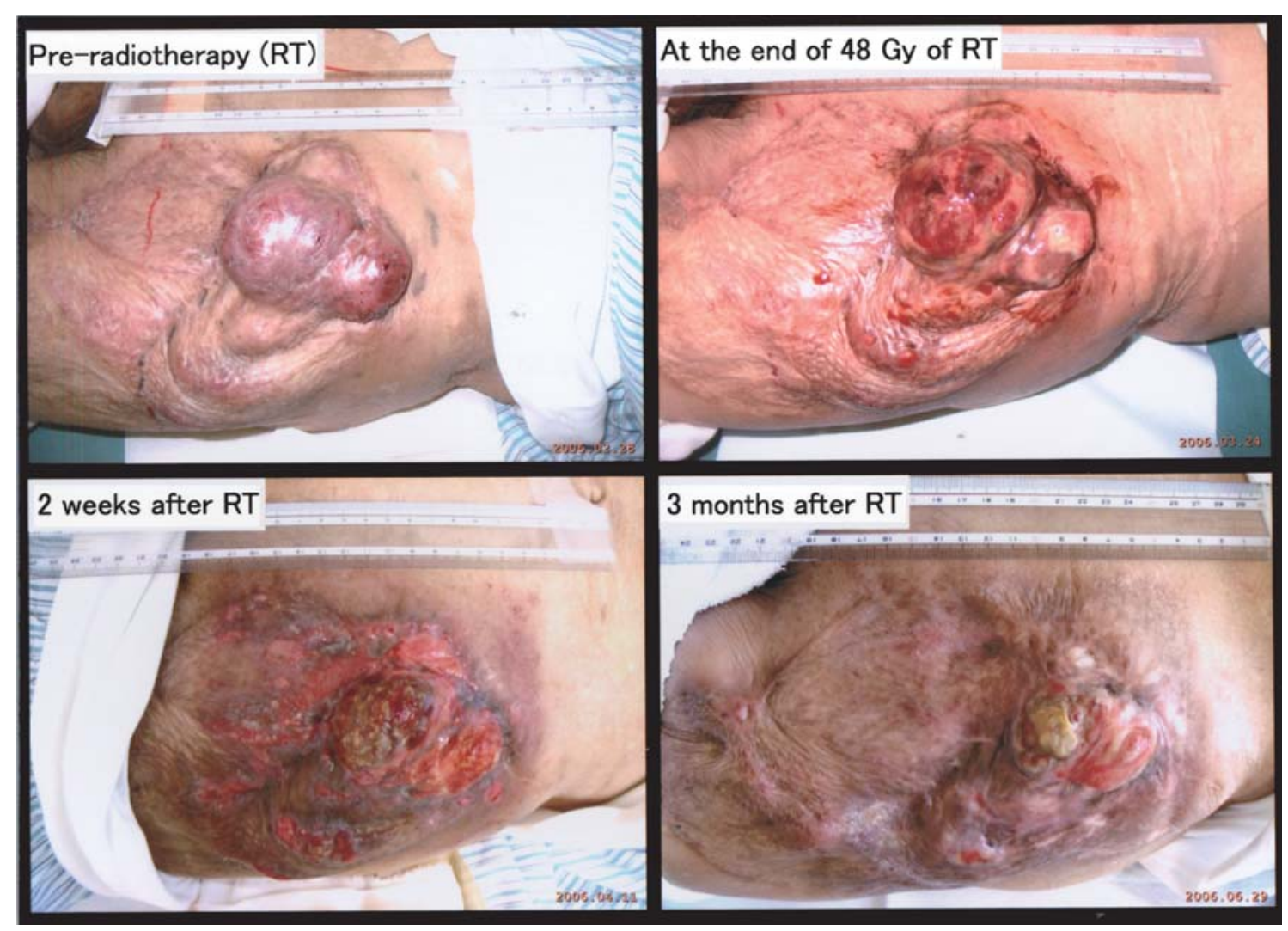

Figure 3. The changes regarding the local findings of the patient (87-year-old male) with unresectable malignant fibrous histiocytoma are shown.

pretreatment volume 3 months following the end of the KORTUC I treatment, and the treatment effect was evaluated as a clinically partial response (cPR).

Another patient (63-year-old female) with recurrent and unresectable extramammary Paget's disease of her vaginal region with direct invasion into the distal urethra also showed a complete response without any complications excluding mild mucositis (figure not shown due to the disease site involved).

In Fig. 4, the changes regarding the local findings of the patient (51-year-old female) with unresectable breast cancer are shown. The large tumor showed a decrement of more than half of the pretreatment volume 1 month following the end of the KORTUC I treatment, and the treatment effect was evaluated as a clinically partial response (cPR).

In Fig. 5, the changes regarding the local findings of the patient (66-year-old female) with post-operatively relapsed and unresectable skin cancer on the right inguinal region are shown. The lesion showed a decrement of more than half of the pretreatment volume 1 month following the end of the KORTUC I treatment, and the treatment effect was evaluated as a clinically partial response (cPR).

\section{Discussion}

Radiation therapy is now performed worldwide, and the number of patients receiving radiation therapy continues to increase. Currently, although most radiation therapy is performed using X-rays or high-energy electron beams from a linear accelerator, these beams are not ideal in terms of the characteristics of low-linear energy transfer (LET). As almost two-thirds of the radiation-induced damage to cancer cells of these low-LET beams such as X-rays and high-energy electron beams is brought about by the production of reactive oxygen species (ROS) in each cell receiving irradiation (9), the existence of oxygen is essential for oxidizing the radicals produced by irradiation. In contrast, the existence of antioxidative enzymes, such as peroxidase, exerts the effect of scavenging radicals produced by irradiation, resulting in a decreased irradiation effect.

It is therefore necessary to develop a new method that inactivates anti-oxidative enzymes and produces oxygen in topical tumor tissue to strengthen the effects of X-rays and high-energy electron beams for low-LET radioresistant tumors such as malignant melanoma, malignant fibrous histiocytoma (MFH), various types of sarcomas and most of the relatively large neoplasms that are frequently seen in daily clinical practice.

Previous studies have demonstrated the ability of hydrogen peroxide to induce apoptosis in numerous types of cells (10-13). Hydrogen peroxide is a simple molecule but has been shown to play an important role in intracellular signal transduction mechanisms. Downstream signaling events that are modulated by hydrogen peroxide include calcium mobilization, protein phosphorylation and gene expression (14). Excess amounts of exogenous hydrogen peroxide are considered to have rapid and potentially disastrous effects on the ability of individual cells to scavenge ROS. In addition, exogenous hydrogen peroxide can increase intracellular hydrogen peroxide accumulation (15) and activate MAPK (mitogen-activated protein kinase) pathways (16), possibly 


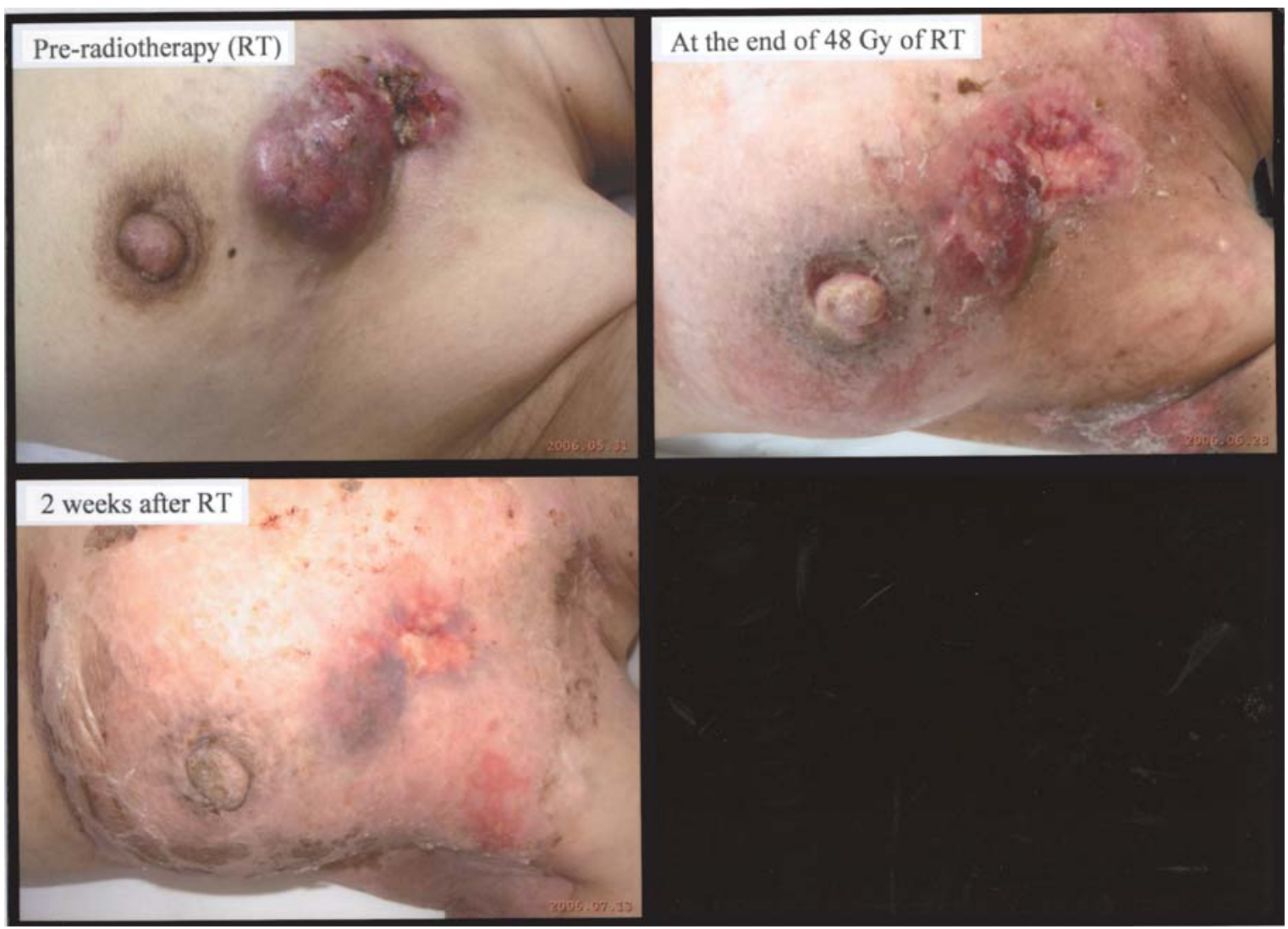

Figure 4. The changes regarding the local findings of the patient (51-year-old female) with unresectable breast cancer are shown.
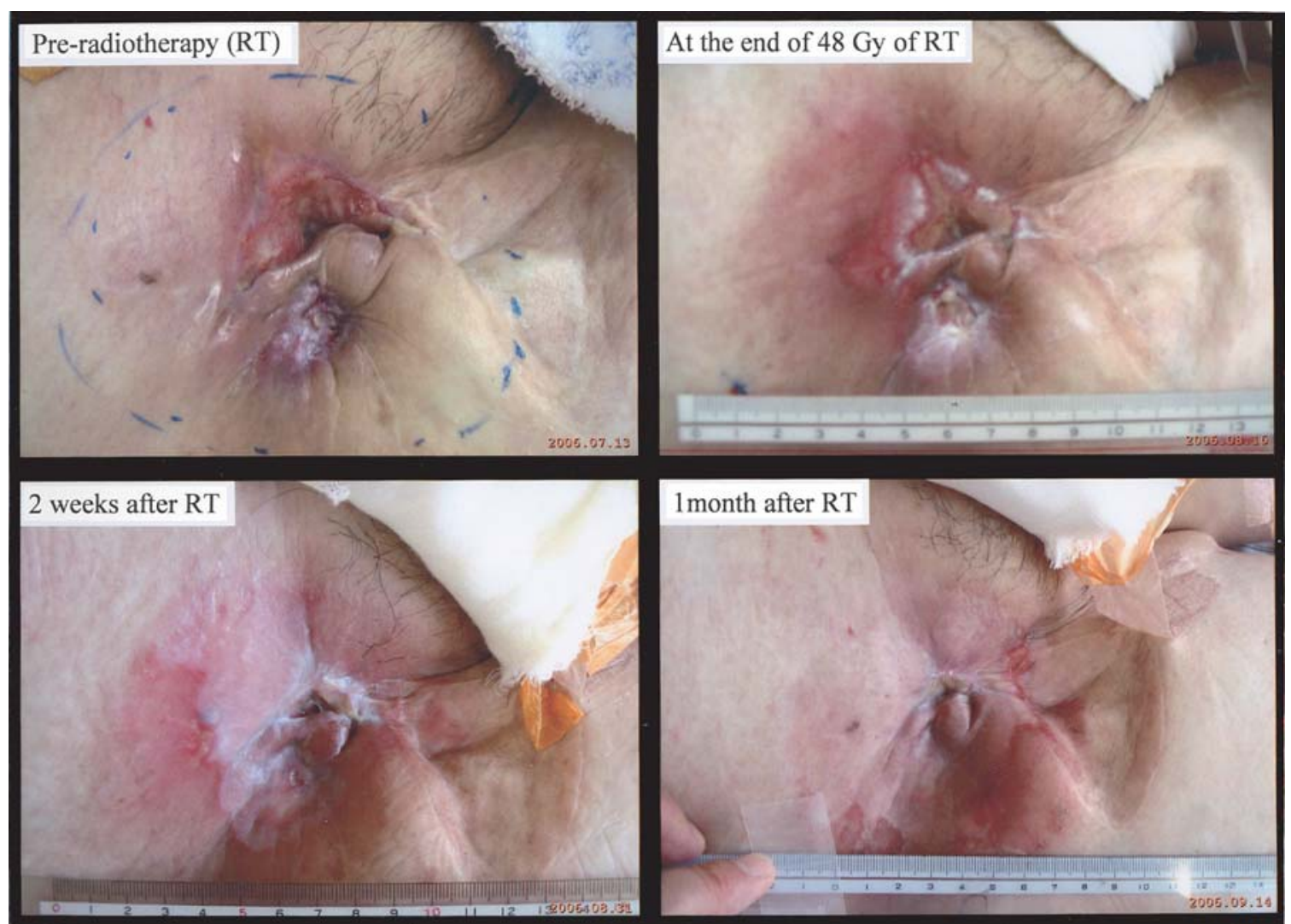

Figure 5. The changes regarding the local findings of the patient (66-year-old female) with post-operatively relapsed and unresectable skin cancer on the right inguinal region are shown. 
resulting in mitochondrial dysfunction and amplification of the oxidative death cycle (17).

We previously elucidated the powerful radiosensitizing effects of hydrogen peroxide (6-8), and we therefore intend to utilize this effect clinically for patients with superficially exposed unresectable malignant neoplasms. As shown in the present results, the radiosensitization effect of our newly developed KORTUC I method was highly successful.

On the basis of the experimental and clinical results mentioned above, we concluded that the KORTUC I radiosensitizing treatment method is extremely valuable for the radiation treatment of superficially exposed and unresectable radioresistant neoplasms. This treatment method can be applied for numerous types of unresectable neoplasms at various tumor sites, by establishing the appropriate drug delivery systems (DDS) for hydrogen peroxide most suitable for each tumor site.

This method is easy and relatively inexpensive and is easily applicable to patients worldwide who present with superficially exposed unresectable neoplasms. Moreover, we have already developed and started the clinical application of a new radiosensitizer containing hydrogen peroxide for topical tumor injection under an ultrasonographical guide for patients with breast cancer, hepatocellular carcinoma and pancreatic cancer. Since there are many more patients suffering from non-superficially exposed neoplasms, the development of a new radiosensitizer for topical tumor injection is considered to be highly valuable for strengthening the therapeutic effects of X-rays and high-energy electron beams from the linear accelerator currently used worldwide.

\section{References}

1. Lawrence TS, Blackstock AW and McGinn C: The mechanism of action of radiosensitization of conventional chemotherapeutic agents. Semin Radiat Oncol 13: 13-21, 2003.

2. Bohm L, Roos WP and Serafin AM: Inhibition of DNA repair by pentoxifylline and related methylxanthine derivatives. Toxicology 193: 153-160, 2003.

3. Milas L: Cyclooxygenase-2 (COX-2) enzyme inhibitors as potential enhancers of tumor radioresponse. Semin Radiat Oncol 11: 290-299, 2001.

4. Choy $\mathrm{H}$ and Milas L: Enhancing radiotherapy with cyclooxygenase-2 enzyme inhibitors: A rational advance? J Natl Cancer Inst 95: 1440-1452, 2003.
5. Overgaad J: Clinical evaluation of nitroimidazoles as modifiers of hypoxia in solid tumors. Oncol Res 6: 509-518, 1994.

6. Ogawa Y, Takahashi T, Kobayashi T, Kariya S, Nishioka A, Mizobuchi H, Noguchi M, Hamasato S, Tani T, Seguchi H, Yoshida S and Sonobe H: Mechanism of apoptotic resistance of human osteosarcoma cell line, HS-Os-1, against irradiation. Int J Mol Med 12: 453-458, 2003.

7. Ogawa Y, Takahashi T, Kobayashi T, Kariya S, Nishioka A, Ohnishi T, Saibara T, Hamasato S, Tani T, Seguchi H, Yoshida $\mathrm{S}$ and Sonobe H: Apoptotic-resistance of the human osteosarcoma cell line HS-Os-1 to irradiation is converted to apoptotic-susceptibility by hydrogen peroxide: a potent role of hydrogen peroxide as a new radiosensitizer. Int $\mathbf{J}$ Mol Med 12: 845-850, 2003.

8. Ogawa Y, Takahashi T, Kobayashi T, Kariya S, Nishioka A, Hamasato S, Moriki T, Seguchi H, Yoshida S and Sonobe H: Immunocytochemical characteristics of human osteosarcoma cell line HS-Os-1: Possible implication in apoptotic resistance against irradiation. Int J Mol Med 14: 397-403, 2004.

9. Hall EJ (ed): The oxygen effect and reoxygenation. In: Radiobiology for the Radiologist. 5th edition JB Lippincott Co., Philadelphia, pp91-111, 2000.

10. Wagner BA, Britigan BE, Reszka KJ, McCormick ML and Burns CP: Hydrogen peroxide-induced apoptosis of HL-60 human leukemia cells is mediated by the oxidants hypochlorous acid and chloramines. Arch Biochem Biophys 401: 223-234, 2002.

11. Li JM, Zhou H, Cai Q and Xiao GX: Role of mitochondrial dysfunction in hydrogen peroxide-induced apoptosis of intestinal epithelial cells. World J Gastroenterol 9: 562-567, 2003.

12. Barbouti A, Doulias PT, Nousis L, Tenopoulou M and Galaris D: DNA damage and apoptosis in hydrogen peroxide-exposed Jurkat cells: bolus addition versus continuous generation of $\mathrm{H}_{2} \mathrm{O}_{2}$. Free Radic Biol Med 33: 691-702, 2002.

13. Frossi B, Tell G, Spessotto P, Colombatti A, Vitale G and Pucillo $\mathrm{C}: \mathrm{H}_{2} \mathrm{O}_{2}$ induces translocation of APE/Ref- 1 to mitochondria in the Raji B-cell line. J Cell Physiol 193: 180-186, 2002.

14. Neil S, Desikan R and Hancock J: Hydrogen peroxide signaling. Curr Opin Plant Biol 5: 389-395, 2002.

15. Maxwell DP, Nickels R and McIntosh L: Evidence of mitochondrial involvement in the transduction of signals required for the induction of genes associated with pathogen attack and senescence. Plant J 29: 269-279, 2002.

16. Kovtun Y, Chiu W-L, Tena G and Sheen J: Functional analysis of oxidative stress-activated mitogen-activated protein kinase cascade in plants. Proc Natl Acad Sci USA 97: 2940-2945, 2000 .

17. Van Camp W, Van Montagu and Inze D: $\mathrm{H}_{2} \mathrm{O}_{2}$ and NO: redox signals in disease resistance. Trends Plant Sci 3: 330-334, 1998. 